\title{
Investigation of in vitro Enzyme Inhibitory Properties and Antioxidant Activity of Moltkia coerulea (Willd.) Lehm. (Boraginaceae) Growing in Raman Mountain - Batman
}

\author{
Alevcan Kaplan (iD) 1,* \\ ${ }^{1}$ Sason Vocational School, Department of Crop and Animal Production, University of Batman, 72060 Batman, \\ Turkey
}

Abstract: The province of Batman is located in the Southeastern Anatolia Region of Turkey, and it is significant in terms of its ecosystem and plant biological diversity. Recently, researching economically important plant species has become a necessity in the province. In this context, while the members of the Boraginaceae genus have found a wide application area in traditional medicine in many countries from ancient times until today, they have been used for many purposes in Turkey. Most of the members of this family are medically important plants containing secondary metabolites such as flavonoids, terpenoids, alkaloids, fatty acids, glycosides, phytosterols, and various proteins. Moltkia coerulea (Willd.) Lehm. is found Anatolia, Lebanon and Crimea. This study aimed to determine the enzyme inhibition and antioxidant activity of $M$. coerulea (Willd.) Lehm, which has not been studied before, and grows in the untouched Raman Mountain in Batman. $\alpha$-amylase and $\alpha$-glucosidase inhibition results of methanolic $(\mathrm{MeOH})$ and aqueous $(\mathrm{Aq})$ extracts of $M$. coerulea were calculated as acarbose equivalents (ACAEs/g extract). Tyrosinase inhibition results of $\mathrm{MeOH}$ and Aq extracts of $M$. coerulea were calculated as kojic acid equivalent (mmol KAEs/g extract). Additionally, the extracts were tested against the 2,2-diphenyl1-picrylhydrazyl (DPPH•) free-radical to analyze their antioxidant activity. The highest antioxidant activity was found in the leaf extract $(\mathrm{MeOH})$ as $61.2 \%$ with for the DPPH • method. These results showed that $M$. coerulea could be used as a potential source of natural antioxidant.

\section{ARTICLE HISTORY}

Received: June 09, 2021

Revised: Sept. 06, 2021

Accepted: Sept. 26, 2021

\section{KEYWORDS}

Antioxidant activity, Enzyme inhibition, Moltkia Lehm.

\section{INTRODUCTION}

The Boraginaceae family is represented in the world with 130 genera and 2300 species, mainly annual, biennial or perennial herbs and shrubs, some trees and a few lianas, and it is distributed in temperate and subtropical areas of the Northern and Southern Hemispheres (Akçin \& Binzet 2009; Tufa et al., 2019). In the last arrangement made by APG IV (2016), in light of molecular phylogeny, the Boraginaceae family was placed in the order Boraginales, which was formed within the clades of Eudicots - Superasterids - Asterids and Lamiids (Chacon et al., 2016).

\footnotetext{
*CONTACT: Alevcan Kaplan $\square$ kaplanalevcan@gmail.com Sason Vocational School, Department of Crop and Animal Production, University of Batman, 72060 Batman, Turkey
} 
In Turkey, it includes 357 taxa, including 34 genera, 325 species, 16 subspecies, and 16 varieties. Turkey ranks in top 10 with the broadest distribution of taxa in the Boraginaceae family. Of these, 31 genera and 320 species naturally grow; 3 genera and 5 species are cultivated, 1 species is naturalized, and there are 2 types of hybrids. Among the natural species, the endemism rate was reported as $42.2 \%$ (Davis 1978; Y1ldirım 2000). Most plants belonging to the family are used as ornamental plants and obtain spices and dyestuffs (Pehlivan et al., 2001). The family includes important plants that have a wide range of use in medicine, pharmacology and cosmetics. The therapeutic effect of these herbs is related to their contents of many biologically active compounds, including naphthoquinones, flavonoids, terpenoids, and phenols. Components isolated from these plants exhibit antimicrobial, antitumor, antiviral, anti-inflammatory, cardiotonic, contraceptive and antiplatelet activities (Sharma et al., 2009; Papp et al., 2011; Taravati et al., 2014; Dresler et al., 2017). M. coerulea, which constitutes the biological material of this study, belongs to the Boraginaceae family. The vernacular name of this species is "Mavi kesen". In the Anti-Taurus Mountains in the province of Niğde in Turkey, the flowers of the plant are consumed by children because of their taste, while its flowers and roots are also used to treat diarrhea and abdominal pain (Özdemir \& Alpınar 20102011; Özdemir \& Alpınar 2015). In Sivas, the leaves of M. coerulea are consumed as food (Orhan et al., 2021).

The $\alpha$-amylase and $\alpha$-glucosidase enzymes are key enzymes involved in carbohydrate digestion. Oligosaccharides such as starch, $\alpha$-dextrin, maltose are hydrolyzed by amylase. $\alpha$ glucosidase hydrolyzes disaccharides and oligosaccharides into glucose units in the small intestines (Sing et al.,2010). Therefore, the inhibition of $\alpha$-amylase and $\alpha$-glucosidase enzymes is an important strategy in reducing increased blood glucose levels (Laube 2002). Drugs that lower blood glucose levels have side effects such as severe hypoglycemia, lactic acidosis, neurological disorders, upset stomach, headache, and even death. Considering the side effects of the long-term use of insulin and other hypoglycemic drugs, it is needed to develop safe and effective drugs, especially plant-based ones (Grover et al., 2002; Watkins 2003). Different traditional medical systems use raw plant extracts or active compounds derived from the plant to treat diabetes. Additionally, after the recommendation made by the World Health Organization (WHO), research on the hypoglycemic activities of medicinal plants has become more important (WHO 1980). The literature review in this study revealed that there are few studies (such as Zengin et al., 2017; Orhan et al., 2021) on Moltkia species that grow or are grown in Turkey. The fact that the area where the study material was collected had not been investigated reveals the necessity of shedding light on the properties of this plant in the area. Moreover, this study was needed for reasons such as differences like the altitudes of the habitats of plants and the soil structure affecting the secondary metabolites produced by plants. Thus, in this study, I aimed to investigate the in vitro enzyme inhibitory properties and antioxidant activity of the $\mathrm{MeOH}$ and aq extracts of the dried and ground parts (above-ground parts: leaves and flowers) of Moltkia coerulea (Willd.).

\section{MATERIAL and METHODS}

\subsection{Plant Material}

Moltkia coerulea which constitutes the study material, was collected from the campus of Batman University during the vegetation period in May 2020 (Figure 1). The botanical identity of the plant was confirmed by Dr. Alevcan Kaplan. Voucher specimens have been deposited at Batman University (voucher no.2020/12). The plants collected have been identified using the $6^{\text {th }}$ volume of the Flora of Turkey (Davis 1978). The collected plant was washed to remove impurities and dried in the shade at room temperature. The samples obtained were ground in the blender. 


\subsection{Plant Extraction}

The $\mathrm{Aq}$ and $\mathrm{MeOH}$ extracts of dried and ground plant parts (above-ground parts: leaves and flowers) were prepared. First of all, the aq extract was prepared. The dried and ground plant parts were extracted with $100 \mathrm{~mL}$ hot water $(2 \% \mathrm{w} / \mathrm{v})$ for 6 hours on a heated magnetic stirrer and filtered. The residues were then recovered with $100 \mathrm{~mL}$ of water, again using the same procedure. The filtered aq extracts were combined, lyophilized and stored at $+4{ }^{\circ} \mathrm{C}$ pending experiments. After this, the $\mathrm{MeOH}$ extract was prepared. The dried and ground plant parts were treated with $200 \mathrm{~mL}$ of $\mathrm{MeOH}$ on a shaker for one day (24 hours) at room temperature and then filtered. This process was repeated with the same procedure. Finally, the extracts were pooled and concentrated using a rotary evaporator.

\subsection{Enzyme Inhibitory Activity}

\subsection{1. a-amylase inhibitory activity}

For determining $\alpha$-amylase inhibition, a $25 \mu \mathrm{L}$ sample of the extract ( $\mathrm{Aq}$ and $\mathrm{MeOH}$ ), and 50 $\mu \mathrm{L}$ of an $\alpha$-amylase solution prepared in a sodium phosphate buffer ( $\mathrm{pH}$ 6.9) were added to test tubes, and the samples were incubated at $37^{\circ} \mathrm{C}$ for 10 minutes. The reaction was initiated by adding $50 \mu \mathrm{L}$ of a starch solution to the wells. A blank was prepared containing denatured enzyme samples. The samples and the blank were incubated at $37{ }^{\circ} \mathrm{C}$ for 10 minutes. The reaction was stopped by adding $25 \mu \mathrm{L}$ of $1 \mathrm{M} \mathrm{HCl}$, and $100 \mu \mathrm{L}$ of a potassium iodide solution was added. Samples and blank were read at $630 \mathrm{~nm}$. The $\alpha$-amylase inhibition effect of the extracts were expressed in units of mmol Acarbose equivalent per $\mathrm{g}$ dry weight (mmol ACAEs/g extract) (Sarıkurkcu et al., 2018).

\subsection{2. $\alpha$-glucosidase inhibitory activity}

For determining $\alpha$-glucosidase inhibition activity, $50 \mu \mathrm{L}$ of the extract (Aq and $\mathrm{MeOH}), 50$ $\mu \mathrm{L}$ glutathione, $50 \mu \mathrm{L} \alpha$-glucosidase solution prepared in a phosphate buffer $(\mathrm{pH}$ 6.8) and 50 $\mu \mathrm{L}$ 4-N-trophenyl- $\alpha$-D-glucopyranoside. (PNPG) were added into test tubes, and the resulting samples were incubated at $37{ }^{\circ} \mathrm{C}$ for 15 minutes. A blank containing denatured enzyme samples was also prepared. The reaction was stopped by adding $50 \mu \mathrm{L}$ of $0.2 \mathrm{M}$ sodium carbonate. The samples and the blank were read at $400 \mathrm{~nm}$. Acarbose, an $\alpha$-glucosidase inhibitor, was chosen as a reference. The $\alpha$-glucosidase inhibition effect of the extracts were expressed in units of mmol Acarbose equivalent per g dry weight (mmol ACAEs/g extract) (Sarıkurkcu et al., 2018).

\subsubsection{Tyrosinase inhibitory activity}

To determine tyrosinase inhibition activity, $25 \mu \mathrm{L}$ of the aq and $\mathrm{MeOH}$ extracts, $100 \mu \mathrm{L}$ of a phosphate buffer ( $\mathrm{pH}$ 6.8) and $40 \mu \mathrm{L}$ of a tyrosinase solution were added, and the samples were incubated at $25^{\circ} \mathrm{C}$ for 15 minutes. The reaction was initiated by adding $40 \mu \mathrm{L}$ of an L-DOPA solution to the tubes. A blank containing denatured enzyme samples was also prepared. The samples and the blank were read at $492 \mathrm{~nm}$ after waiting for 10 minutes and at $25{ }^{\circ} \mathrm{C}$. The tyrosinase inhibition activity of the extracts were expressed in mmol kojic acid equivalent per g dry weight (mmol KAEs/g extract) (Sarıkurkcu et al., 2018).

\subsection{Antioxidant Activity}

\subsubsection{DPPH scavenging activity}

Free radical activities of the extracts were determined using the DPPH free radical (Gezer et al., 2006). For the experiment, the concentrate was prepared by dissolving $4 \mathrm{mg}$ DPPH in 100 $\mathrm{mL}$ MeOH. $3.2 \mathrm{~mL}$ of the DPPH radical and $200 \mu \mathrm{L}(500 \mu \mathrm{g} / \mathrm{mL})$ of the extract solutions were 
added for each sample. After 30 minutes of incubation at room temperature in the dark, absorbance was measured at $517 \mathrm{~nm}$. For control, $200 \mu \mathrm{L}$ of the extract solution was added to the test tube. Each trial was made with triplicate. The following formula was used to determine the \% DPPH radical scavenging activities of the samples.

$$
\% \text { DPPH scavenging activity }=\left[\left(\mathrm{A}_{\text {control }}-\mathrm{E}_{\text {extract }}\right) / \mathrm{A}_{\text {control }}\right] \times 100
$$

\subsection{Statistical Analysis}

All experiments in the study were carried out in triplicates. For the DPPH assay, the \% scavenging activities of the samples were calculated using the Microsoft Excel program, and standard error bars were added to the plots. For the other analysis, the descriptive statistical data (Mean \pm Standard Deviation) of the variables are shown in tables. The statistical analysis were performed using SPSS for Windows (version 21.0).

\section{RESULTS and DISCUSSION}

M. coerulea which constitutes the study material, was collected from the campus of Batman University during the vegetation period in May 2020 (Figure 1).

Figure 1. Natural photos of Moltkia coerulea: A- general view of plant, B- flowering part.

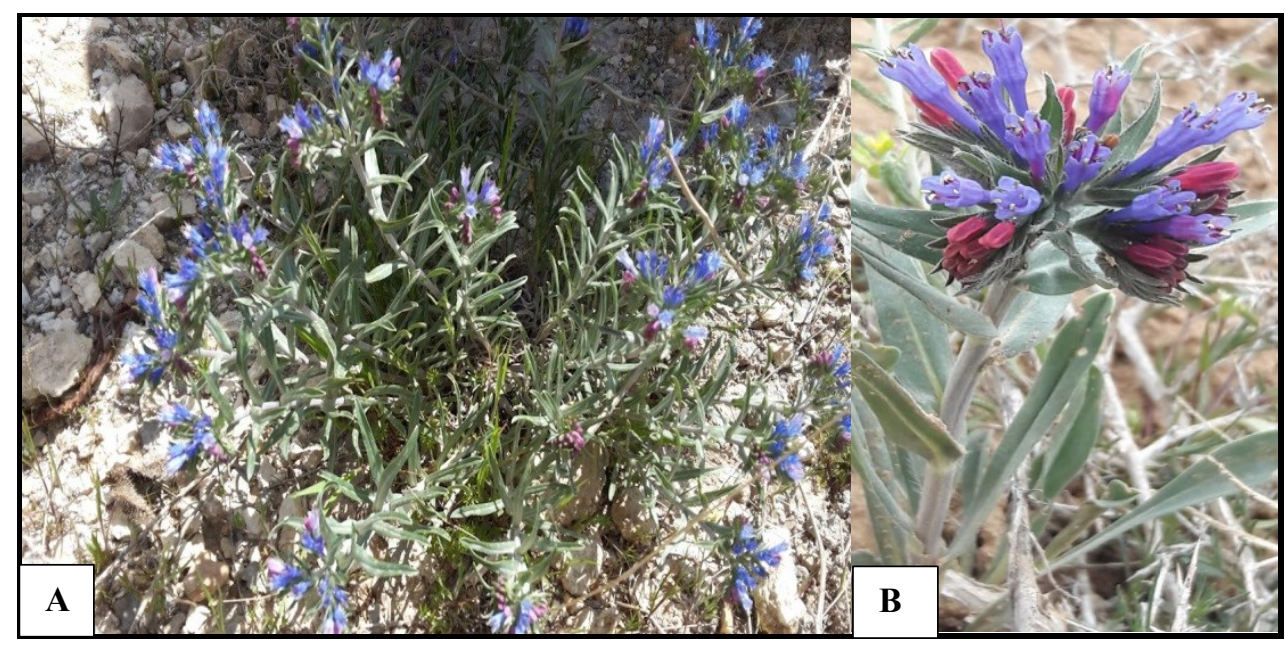

The yield amounts of the extracts are given in Table 1. Accordingly, when the effects of the solvents on the yield were examined based on due to the extraction process, the highest performance in terms of the two different solvents was obtained in the experiments using the aq as a solvent. A lower yield was obtained when $\mathrm{MeOH}$ was used as the solvent. The inhibitory effects of the $\mathrm{Aq}$ and $\mathrm{MeOH}$ extracts of $M$. coerulea against three different enzymes were determined (Table 2).

Table 1. Extract yields of Moltkia coerulea in the Aq and $\mathrm{MeOH}$ solvents.

\begin{tabular}{cccc}
\hline Samples & Solvent system & $\%$ & $\mathrm{mg} / \mathrm{g}$ dry matter \\
\hline MCL & $\mathrm{Aq}$ & 21.37 & 213.7 \\
$\mathrm{MCL}$ & $\mathrm{MeOH}$ & 11.12 & 111.2 \\
$\mathrm{MCF}$ & $\mathrm{Aq}$ & 21.65 & 216.5 \\
$\mathrm{MCF}$ & $\mathrm{MeOH}$ & 12.15 & 121.5 \\
\hline
\end{tabular}

MCL: Moltkia coerulea leaf; Moltkia coerulea flower

\pm standard deviation was used. $\mathrm{n}: 3$ 
Table 2. Enzyme inhibitory activities of the $\mathrm{Aq}$ and $\mathrm{MeOH}$ extract of M. Coerulea.

\begin{tabular}{ccclll}
\hline \multirow{2}{*}{ Sample } & Part & $\begin{array}{c}\text { Extract } \\
\text { type }\end{array}$ & $\begin{array}{l}\alpha \text {-amylase } \\
\text { inhibition activity } \\
\text { (mmol ACAEs/g } \\
\text { extract) }\end{array}$ & $\begin{array}{l}\alpha \text {-glucosidase } \\
\text { inhibition activity } \\
\text { (mmol ACAEs/g } \\
\text { extract) }\end{array}$ & $\begin{array}{l}\text { Tyrosinase inhibition } \\
\text { activity (mmol } \\
\text { KAEs/g extract) }\end{array}$ \\
\hline \multirow{3}{*}{ M.coerulea } & Leaf & $\mathrm{Aq}$ & $0.296 \pm 0.12$ & $0.481 \pm 0.06$ & $0.860 \pm 0.00$ \\
\cline { 2 - 6 } & Flower & $\mathrm{MeOH}$ & $0.325 \pm 0.01$ & $0.610 \pm 0.01$ & $0.761 \pm 0.00$ \\
\hline & $\mathrm{AeOH}$ & $0.450 \pm 0.05$ & $0.516 \pm 0.22$ & $0.480 \pm 0.01$ \\
& & $0.358 \pm 0.07$ & $0.524 \pm 0.71$ & $0.610 \pm 0.04$ \\
\hline
\end{tabular}

KAE: Kojic acid equivalent; ACAE: Acarbose equivalent

Values expressed are means \pm S.D. of three parallel measurements

Diabetes is characterized by chronic hyperglycemia and has become a significant health problem all over the world. A consistently high glucose level in the blood leads to cardiovascular disease, neuropathy, retinopathy, nephropathy and other disorders. Hypoglycemic drugs used today manage to normalize serum glucose levels, but they cause gastrointestinal complaints. Thus, it is important to find effective therapeutic agents that inhibit $\alpha$-amylase and $\alpha$-glucosidase and have no side effects (Liu et al., 2017). The $\alpha$ glucosidase and $\alpha$-amylase inhibition effects of the $\mathrm{Aq}$ and $\mathrm{MeOH}$ extracts of the flowers and leaves of the $M$. coerulea plant are shown in Table 2. The $\alpha$-amylase inhibition effect of the $\mathrm{Aq}$ and $\mathrm{MeOH}$ (0.450 and $0.358 \mathrm{mmol} \mathrm{ACAEs} / \mathrm{g}$ extract, respectively) extracts of flowers was stronger than the Aq and $\mathrm{MeOH}$ (0.296 and 0.325 ACAEs/g extract, respectively) extracts of leaves. The $\alpha$-glucosidase inhibition effect of the $\mathrm{Aq}$ and $\mathrm{MeOH}(0.481$ and $0.610 \mathrm{mmol}$ ACAEs/g extract, respectively) extracts of leaves was closest with the Aq and $\mathrm{MeOH}(0.516$ and $0.524 \mathrm{mmol}$ ACAEs/g extract, respectively) extracts of flowers. In general, the results obtained in this study on the $\alpha$-amylase inhibition effects of the extracts were similar to those reported in the literature. The $\alpha$-glucosidase inhibition effects of the extracts in this study were lower than those in some studies and higher than those in some others (Zengin et al., 2017; Orhan et al., 2020). The different substrates can explain these differences in the inhibition of two enzymes that affect sugar metabolism.

Likewise, in various studies investigating the enzyme inhibition effects of phenolic compounds, some phenolic compounds have been reported to have effective glycosidase inhibition activities (Kubola et al., 2008; Vadivel \& Biesalksi, 2011; Wang et al., 2012). This also explains the inverse relationship between the consumption of foods rich in phenolic compounds and diabetes rates. Moreover, tyrosinase is a key enzyme that catalyzes the production of the pigment melanin that helps prevent damage induced by UV light exposure. Melanin synthesis occurs in melanocytes by the transformation of tyrosine into dihydroxy phenylalanine (DOPA), then DOPA-quinone, and then into black-brown eumelanin and yellow-red pheomelanin via the tyrosinase enzyme. With this function, tyrosinase is takes part in the formation of skin and hair color (Canovas et al., 1982; Rodriguez-Lopez et al., 1991; Cooksey et al., 1997). Its excess can lead to hyperpigmentation and neurodegenerative diseases such as Parkinson's disease. Although many synthetic inhibitors, especially kojic acid, have been developed to inhibit tyrosinase activity, the long-term toxic effects of these inhibitors have made their use questionable, and studies to determine natural inhibitors as alternatives to these have become the focus of attention (Tocco et al., 2009). Accordingly, in line with the data obtained it this study, the inhibitory effect of the $\mathrm{Aq}$ and $\mathrm{MeOH}(0.860$ and $0.761 \mathrm{mmol} \mathrm{KAEs} / \mathrm{g}$ extract, respectively) leaf extracts on the tyrosinase enzyme was stronger than that of the $\mathrm{Aq}$ and $\mathrm{MeOH}(0.480$ and $0.610 \mathrm{mmol} \mathrm{KAEs} / \mathrm{g}$ extract, respectively) flower extracts. Zengin et al. (2017), also determined that the aeiral parts of the plant samples' extract 
of the same plant was more effective in inhibiting the tyrosinase enzyme $(34.97 \pm 0.50 \mathrm{mg}$ $\mathrm{KAEs} / \mathrm{g}$ extract). In addition, they stated that rutin, which is the major compound with phenolic groups, has been previously reported to inhibit tyrosinase through an inhibitory mechanism similar to that of copper chelators. That is, rutin competes competitively with the substrate LDOPA in the active site pocket, inducing hydrophobic surface exposure (Si et al., 2012; Zengin et al., 2017).

Oxidative stress is recognized as the main pathological trigger for many diseases, including type II diabetes and Alzheimer's. Antioxidants are thought to be therapeutic tools to inhibit the activity levels and formation of oxidative stress (Liu et al., 2017). In this study, the antioxidant capacity of the $\mathrm{MeOH}$ and aq extracts of M.coerulea was determined using the DPPH test (Figure 2). The DPPH radical is widely used to evaluate free radical scavenging activity due to its ease of reaction. When the DPPH radical is scavenged with an antioxidant compound through hydrogen donation to form a stable DPPH-H molecule, the color of the solution turns from purple to yellow (Gangwar et al., 2014). If the results of this study are evaluated in general, it may be stated that the $\mathrm{MeOH}$ extracts of leaves and flowers (MeOHLE $61.2 \%$ and MeOHFE $40.17 \%$, respectively) showed a better DPPH scavenging activity than the aq extracts (AqLE $25.1 \%$; AqFE $20.4 \%$ ). Konc 'ic' et al. (2010) collected the leaves of the Moltkia petraea plants from two regions named Sveti Jure and Snijez nica in Croatia, and they found that the leaves of the plants collected from the Sniježnica locality generally showed better antioxidant activity than the ones collected from the Sveti Jure locality. Orhan et al. (2021) investigated in the in vitro enzyme inhibition properties, antioxidant and phytochemical profiles antimicrobial and anti-tyrosinase activity of $M$. aurea and M. coerulea. As a result of their analysis of the total antioxidant capacity, they revealed that the ethyl acetate extracts exhibited a remarkable antioxidant potential compared to the extracts prepared using other solvents. While the superoxide scavenging activity of the water, $\mathrm{MeOH}$ and $\mathrm{EA}$ (ethyl acetate) extracts of the roots of both species was found promising, the $\mathrm{MeOH}$ extracts of all samples had significant DPPH free radical scavenging activities. The researchers stated that the antioxidant and antidiabetic effects of the extracts may have occurred due to their rutin and rosmarinic acid contents. It has been thought that the reason for the variations between $M$. coerulea species collected from different localities and between different species (such as $M$. petraea) in other studies was differences affecting these plants' biochemical and physiological structures such as species, organ, physiological age, harvest time, and locality. Consequently, in this study, it was determined that the plant extracts had a high rate of radical scavenging activity. Based on the results, it is thought that the extracts of $M$. coerulea can be used as natural source of antioxidants in areas such as food, cosmetics and pharmacology, in treatment, as a preservatives and as additives. 
Figure 2. DPPH free radical scavenging activity of Moltkia coerulea extracts. AqLE; aqueous leaf extract, MeOHLE; methanol leaf extract, AqFE; aqueous flower extract, MeOHFE; methanol flower extract.

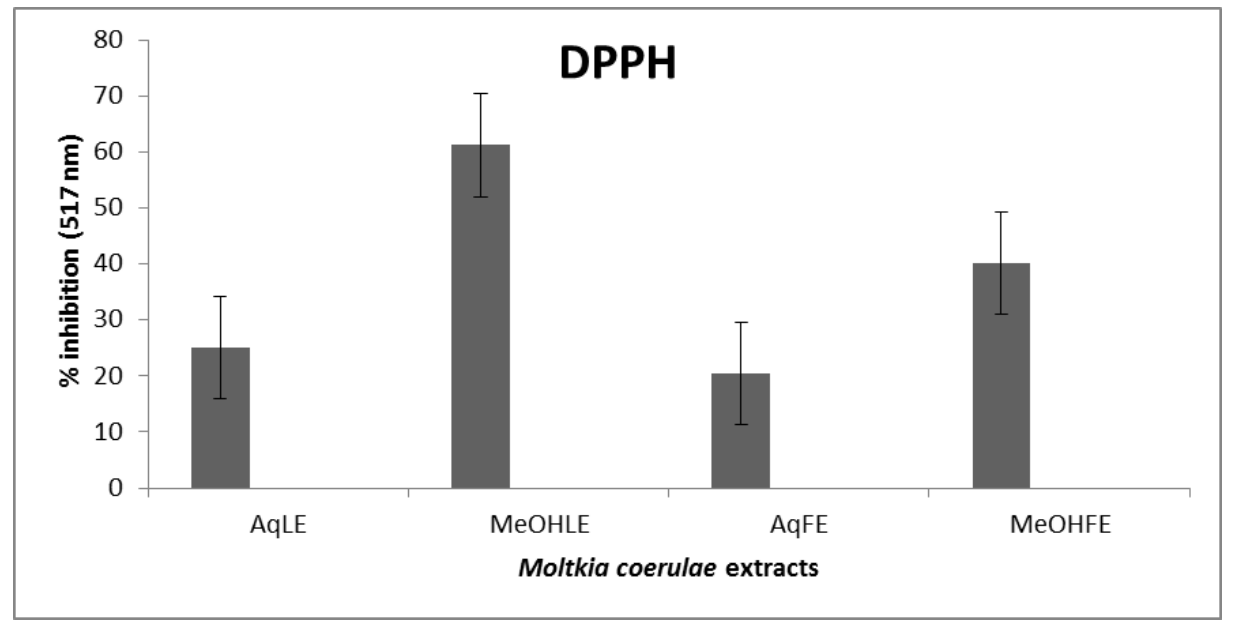

\section{CONCLUSION}

Due to the recently increasing concerns of the public regarding the effects of synthetic compounds on human health, natural compounds have gained a significant position. This field of research has revealed new, safe and natural sources for natural compounds, which are among the most popular topics in the scientific world. The results obtained in this study demonstrated that the extracts of $M$. coerulea can be considered as a source of natural biological agents. Therefore, these results show that the tested M. coerulea plant has a wide range of pharmaceutical uses.

\section{Acknowledgments}

The study was presented as an oral at International Eurasian Conference on Biotechnology and Biochemistry (BioTechBioChem 2020) on 16-18 June in Ankara by the online meeting.

\section{Declaration of Conflicting Interests and Ethics}

The author declares no conflict of interest. This research study complies with research and publishing ethics. The scientific and legal responsibility for manuscripts published in IJSM belongs to the author.

\section{Authorship Contribution Statement}

Alevcan Kaplan: Investigation, Resources, Visualization, Formal Analysis, and Writing original draft.

\section{Orcid}

Alevcan Kaplan (D) https://orcid.org/0000-0001-6738-7527

\section{REFERENCES}

Akçin, Ö.E., \& Binzet, R. (2009). Nutlet size, shape and surface ornamentation in 14 Onosma species (Boraginaceae). Acta Botanica Croatica, 68(1), 117-126.

Canovas, F.G., Garcia-Carmona, F., Sánchez, J.V., Pastor, J.L., Teruel, J.A. (1982). The role of $\mathrm{pH}$ in the melanin biosynthesis pathway. Journal of Biological Chemistry, 257(15), 87388744.

Chacon, J., Luebert, F., Hilger, H., Ovicinnikova, S., Selvi, F., Cecchi, L., Guilliams, C.M., Hasenstab-Lehman, K., Sutory, K.K., Simpson, M.G., \& Weigend, M. (2016). A revised infrafamilial classification of the borago family (Boraginaceae s. str.) based on a molecular 
phylogeny with an emphasis on the placement of some enigmatic genera. Taxon, 65(3), 523546. https://doi.org/10.12705/653.6

Cooksey, C.J., Garratt, P.J., Land, E.J., Pavel, S., Ramsden, C.A., Riley, P.A., Smit, N.P. (1997). Evidence of the indirect formation of the catecholic intermediate substrate responsible for the autoactivation kinetics of tyrosinase. Journal of Biological Chemistry, 272(42), 26226-26235. https://doi.org/10.1074/jbc.272.42.26226

Davis, P.H. (1978). Flora of Turkey and The Aegan Islands. Universty Pres, Vol: VI, Edinburg.

Dresler, S., Szymczak, G., \& Wojcik, M. (2017). Comparison of some secondary metabolite content in the seventeen species of the Boraginaceae family. Pharmaceutical Biology, 55(1), 691-695. https://doi.org/10.1080/13880209.2016.1265986

Gangwar, M., Gautam, M.K., Sharma, A.K., Tripathi, Y.B., Goel, R.K., Nath, G. (2014). Antioxidant Capacity and Radical Scavenging Effect of Polyphenol Rich Mallotus philippenensis Fruit Extract on Human Erythrocytes: An In Vitro Study. The Scientific World Journal, 1-12. https://doi.org/10.1155/2014/279451

Grover, J.K., Yadav, S., Vats, V.( 2002). Medicinal plants of India with anti-diabetic potential. Journal of Ethnopharmacology, 81(1), 81-100. https://doi.org/10.1016/s0378-8741(02)000 $\underline{59-4}$

Konc`ic', M. Z., Kremer, D., Gruz, J., Strnad, M., Biševac, G., Kosalec, I., Šamec, D., PiljacŽegarac, J., Karlovic', K. (2010). Antioxidant and antimicrobial properties of Moltkia petraea (Tratt.) Griseb. flower, leaf and stem infusions. Food and Chemical Toxicology, 48, 1537-1542. https://doi.org/10.1016/j.fct.2010.03.021

Kubola, J., Siriamornpun, S. (2008), Phenolic contents and antioxidant activities of bitter gourd (Momordica charantia L.) leaf, stem and fruit fraction extracts in vitro. Food Chemistry, 110(4), 881-890. https://doi.org/10.1016/j.foodchem.2008.02.076

Laube, H., (2002). Acarbose: An update of its therapeutic use in dia betes treatment. Clinical Drug Investigation, 22, 141-156. https://doi.org/10.2165/00044011-200222030-00001

Liu, S., Ai, Z., Qu, F., Chen, Y., Ni, D. (2017). Effect of steeping temperature on antioxidant and inhibitory activities of green tea extracts against alpha-amylase, alpha-glucosidase and intestinal glucose uptake. Food Chemistry, 234, 168-173. https://doi.org/10.1016/j.foo dchem.2017.04.151

Orhan, N., Gökbulut, A., Deliorman-Orhan, D. (2021). In vitro Enzyme Inhibitory Properties, Antioxidant Activities and Phytochemical Profiles of Moltkia aurea and Moltkia coerulea. Turkish Journal of Pharmaceutical Sciences. 18(2), 204-212. https://doi.org/10.4 274/tjps.galenos.2020.12258

Özdemir, E., Alpınar, K. (2010-2011). The wild edible plants of western Nigde Aladaglar Mountains (Central Turkey). Journal of Faculty of Pharmacy Istanbul University, 41, 6674.

Özdemir, E., Alpınar, K. (2015). An ethnobotanical survey of medicinal plants in_western part of central Taurus Mountains: Aladaglar (Nigde-Turkey). Journal of Ethnopharmacology, 166, 53-65. https://doi.org/10.1016/j.jep.2015.02.052

Papp, N., Bencsik, T., Nemeth, K., Gyergyak, K., Sulc, A., Farkas, A. (2011). Histological study of some Echium vulgare, Pulmonaria officinallis and Symphytum officinale populations. Natural Product Communication, 10, 1475-1478.

Pehlivan, S., Bayrak, F., Aldemir, H., Kılıç, N. (2001). Pollen Morphology, Total Protein and Chemical Analyses in Some Endemic Plant Species in Turkey, Mellifera, 1(2), 50-55.

Rodríguez-López, J.N., Tudela, J., Varón, R., García-Cánovas, F. (1991), Kinetic study on the effect of $\mathrm{pH}$ on the melanin biosynthesis pathway. Biochimica et Biophysica Acta (BBA)Protein Structure and Molecular Enzymology, 1076(3), 379-386. https://doi.org/10.1016/0 $\underline{167-4838(91) 90480-\mathrm{n}}$ 
Sharma, R.A., Singh, B., Singh, D., Chandrawat, P. (2009). Ethnomedicinal, pharmacological properties and chemistry of some medicinal plants of Boraginaceae in India. Journal of Medicinal Plants Research, 13, 1153-1175.

Singh, J., Dartois, A., Kaur, L. (2010). Starch digestibility in food matrix: a review. Trends in Food Science \& Technology, 21(4), 168-180. https://doi.org/10.1016/j.tifs.2009.12.001

Taravati, G., Masoudian, N., Gholamian, A. (2014). Evaluation of medical metabolites in Boraginaceae family. Journal of Chemical Health Risks, 4, 53-61.

Tocco, G., Fais, A., Meli, G., Begala, M., Podda, G., Fadda, M.B., Corda, M., Attanasi, O.A., Filippone, P., Berretta, S. (2009). PEG-immobilization of cardol and soluble polymersupported synthesis of some cardol-coumarin derivatives: Preliminary evaluation of their inhibitory activity on mushroom tyrosinase, Bioorganic \& Medicinal Chemistry Letters, 19(1), 36-39. https://doi.org/10.1016/j.bmcl.2008.11.020

Tufa, T., Damianakos, H., Zengin, G., Graikou, K., Chinou, I. (2019). Antioxidant and enzyme inhibitory activities of disodium rabdosiin isolated from Alkanna sfikasiana Tan, Vold and Strid, South African Journal of Botany, 120, 157-162. https://doi.org/10.1016/j.sajb.2018.0 $\underline{4.005}$

Vadivel, V., Biesalski, H.K. (2011). Contribution of phenolic compounds to the antioxidant potential and type II diabetes related enzyme inhibition properties of Pongamia pinnata L. Pierre seeds. Process Biochemistry, 46(10), 1973. https://doi.org/10.1016/j.procbio.2011 .07 .007

Yildirımlı, Ş. (2000). The chorology of the Turkish species of Boraginaceae family. The Herb Journal of Systematic Botany, 7(2), 257-272.

Wang, Y., Huang, S., Shao, S., Qian, L., Xu, P. (2012), Studies on bioactivities of tea (Camellia sinensis L.) fruit peel extracts: Antioxidant activity and inhibitory potential against $\alpha$ glucosidase and $\alpha$-amylase in vitro, Industrial Crops and Products, 37(1), 520-526. https://doi.org/10.1016/j.indcrop.2011.07.031

Watkins, P.J. (2003). ABC of diabetes: cardiovascular disease, hypertension, and lipids. British Medical Journal, 327 (7405), 17-17. https://doi.org/10.1136/bmj.326.7394.874

WHO, (1980). Expert Committee on Diabetes mellitus. Technical report series. World Health Organization, Geneva.

Zengin, G., Ceylan, R., Katani, J., Mollica, A., Aktumsek, A., Boroja, T., Mati, S., Mihailovi, V., Stani, S., Aumeeruddy-Elalfi Z., Yilmaz, M.A., Mahomoodally, M.F. (2017). Combining in vitro, in vivo and in silico approaches to evaluate nutraceutical potentials and chemical fingerprints of Moltkia aurea and Moltkia coerulea. Food and Chemical Toxicology, 107(2017), 540-553. https://doi.org/doi: 10.1016/j.fct.2017.04.004 